\title{
Gastrointestinal adaptation to enhanced small intestinal lipid exposure
}

\author{
N J Brown, R D E Rumsey, N W Read
}

\begin{abstract}
Studies were performed on 20 male adult rats to investigate the effects of chronic intermittent infusion of lipid and physiological emulsifier into the distal small intestine on stomach to caecum transit time (SCTT) of the head of a test meal. SCTT was measured using environmental hydrogen analysis. Ileal lipid infusion normally delays gastric emptying and small intestinal transit $(p<0.001)$, but chronic intermittent infusion of lipid, given three times a week gradually reduced the delay in transit time until by four weeks it was no longer than control values. The lipid induced delay did not return during the four weeks after the chronic infusion had finished. Intermittent infusion of physiological emulsifier into the distal small intestine for four weeks did not change the control SCTT or the acute response to an ileal lipid infusion. SCTT of the head of the meal did not change in the four weeks after the physiological emulsifier infusion had stopped. In conclusion these results show that infusing rats intermittently with lipid for four weeks results in desensitisation of the mechanisms by which distal small intestinal lipid regulate SCTT of the head of a meal. This adaptation is not reversed within four weeks of withdrawal of the lipid infusion. These results emphasise the importance of assessing recent dietary history when assessing gastric emptying and small bowel transit times

(Gut 1994; 35: 1409-1412)
\end{abstract}

Acute infusion of lipid into the ileum of humans ${ }^{1}$ and experimental animals ${ }^{23}$ delays the transit of a meal through the stomach and small intestine and inhibits food intake. ${ }^{45}$ This finding suggests that administration of capsules that release their contents into the ileum may provide a useful way of controlling food intake and the movement of food through the stomach and small intestine. If this approach is to be of clinical use then repeated administration of the lipid must still continue to delay gastrointestinal transit without adaptation occurring.

Little is known of the possible adaptation of gastrointestinal motility and transit to nutrient content in the diet. The delivery of nutrients from the stomach is retarded in patients with primary anorexia ${ }^{6}$ but this returns to normal rates after two weeks of refeeding. ${ }^{78}$ In contrast some studies have shown rapid gastric emptying in obese subjects. ${ }^{9} 10$ These studies suggest that the small intestinal receptor mechanisms controlling gastric emptying may be up or down regulated by the presence of nutrients. Recent studies in our laboratory have shown that habituation to a high fat diet for two weeks increased the rate of gastric emptying and mouth to caecum transit of a fatty meal $^{11}$ in normal volunteers whereas increased intake of glucose for three days accelerated gastric emptying of a hyperosmotic drink of glucose. ${ }^{12}$ These results again suggest the possibility of intestinal receptor adaptation to ingested nutrients.

The aim of this series of studies was to test the hypothesis that enhanced exposure of small intestinal receptors to nutrients can induce adaptive changes in physiological responses, by investigating whether chronic intermittent lipid infusion into the ileum produces adaptive changes in the lipid induced delay in gastrointestinal transit. Palm oil was used as the ileal infusate in these experiments as it has been shown to profoundly delay stomach to caecum transit time (SCTT) of the head of a meal when infused into the distal small intestine. ${ }^{3}$

\section{Methods}

\section{ANIMALS}

Experiments were carried out on a total of 20 adult male albino rats, obtained from Sheffield Field Laboratories and weighing between 250-330 g. The rats were equipped with chronic indwelling ileal cannulas and housed separately in cages. The animals were deprived of food (Diet 86, Oxoid, London, UK) 18 hours before the experiment but water was available ad libitum. Animals were permitted at least one week postoperative recovery before any experiments were carried out.

PREPARATION OF THE TEST MEAL

'Californian' white beans (H J Heinz Co Ltd, Hayes, Middlesex, UK) were washed to remove the tomato sauce, homogenised with a little water, and lactose (May \& Baker Ltd, Dagenham, UK) was added to produce a concentration of $10 \% \mathrm{wt} / \mathrm{vol}$.

PREPARATION OF THE PALM OIL EMULSION The palm oil, which was solid at room temperature, was melted in a water bath, then emulsified on ice by ultrasound (Soniprep 150, MSE Ltd, Crawley, Sussex, UK) using a physiological emulsifier. This contained $9 \cdot 1 \mathrm{mM}$ glycerol (Sigma Chemical 
Co, St Louis, MO, USA), $16 \cdot 8 \mathrm{mM}$ L-alphaphosphatidyl choline (Sigma Chemical), and $9.4 \mathrm{mM}$ taurocholic acid (Sigma Chemical) in $0.9 \%$ sterile saline (Travenol Laboratories Ltd, Thetford, Norfolk, UK). The resulting solution was isotonic and the $\mathrm{pH}$ was adjusted to $7 \cdot 0$. The emulsifying solution alone was used as a control.

\section{SURGICAL PROCEDURE}

A plastic cannula (Silastic ID 0.02 in, OD 0.037 inches, Dow Corning Corp, Medical Products, Midland, Michigan, USA), $25 \mathrm{~cm}$ in length was implanted in the ileum of animals under barbiturate anaesthesia (Sagatal 60 $\mathrm{mg} / \mathrm{kg}$; May \& Baker Ltd, Dagenham, UK). The abdomen was opened by a midline incision and the cannula placed in the ileal lumen about $20 \mathrm{~cm}$ proximal to the ileocaecal junction. The intestinal wound was closed using a purse string suture around the cannula making sure the lumen of the cannula was not occluded. Sufficient cannula was left free in the abdominal cavity to permit the gastrointestinal tract full mobility. The abdominal wound was closed in two separate layers, the muscle and then the skin using a sterile braided silk suture 5-0 (Mersilk, Ethicon, Edinburgh, Scotland, UK). A small square of nylon mesh was secured $2-3 \mathrm{~cm}$ from the end of the cannula using silicon glue (Medical adhesive type A, Dow Corning Corp, Medical Products, Midland, MI, USA). The cannula was tunnelled subcutaneously from an abdominal stab wound to the midscapular region where it was exteriorised through a cutaneous puncture wound, the piece of nylon mesh lying under the skin forming an anchorage point as the damaged tissues under the skin regenerated. Each rat was permitted a postoperative recovery period of one week before any experimental procedures were performed. Every day a small volume of saline $(0.3 \mathrm{ml})$ was infused into the ileum of each rat to ensure the cannula remained patent.

\section{EXPERIMENTAL PROTOCOLS}

SCTT of the head of the bean meal was initially evaluated on two occasions during ileal infusion of both the emulsifier control solution and the palm oil solution. These experiments were carried out in random order in 20 animals. The animals were then assigned to two equal groups; 10 had chronic ileal infusion of the emulsifier and 10 had chronic ileal infusion of palm oil. These solutions were infused into the ileum for three hours a day on three days a week for a total of four weeks at a rate of $0.3 \mathrm{ml} / \mathrm{h}$, the total infusion volume being $0.9 \mathrm{ml}$. SCTT of the head of the bean meal was assessed each week in the two groups of animals, during either an acute ileal infusion of palm oil into the group receiving chronic intermittent palm oil infusion, or during an acute ileal infusion of physiological emulsifier into the group receiving chronic intermittent emulsifier infusion. At the end of the four weeks of chronic infusions, the effects of an acute ileal infusion of emulsifier in the chronic intermittent lipid group and an acute ileal infusion of lipid into the chronic intermittent emulsifier group was also assessed.

SCTT of the baked bean meal was then assessed each week for a further four weeks after the chronic intermittent infusions had ended to record the time course of any recovery. The effect of an acute infusion of palm oil on SCTT of the head of the meal was assessed in five animals from the chronic intermittent palm oil group and the effect of an acute infusion of physiological emulsifier on SCTT was assessed in five animals from the chronic intermittent emulsifier group.

\section{MEASUREMENT OF STOMACH TO CAECUM TRANSIT TIME}

Rats were starved for 18 hours before experimentation, placed in Bollman restraining cages, and either emulsifier or palm oil solution was infused through an ileal cannula at a rate of $0.3 \mathrm{ml} / \mathrm{h}$ for 30 minutes by means of a syringe pump (Braun, Germany). The rats were then gavaged with $5 \mathrm{ml}$ of the bean/lactose test meal and placed in the Perspex chambers. The infusion tube was attached to a pulley system permitting the animal free movement within the chamber. The infusion continued for another 165 minutes (total infusion volume $0.975 \mathrm{ml}$ ) after gavage. The perspex chambers provided a controlled environment from which the hydrogen concentrations could be monitored easily and solutions infused into the animals with minimal disturbance. The concentration of hydrogen in the rats' environment was analysed at regular intervals by a computerised system using a gas sensitive electrode. The method is described in detail in a previous publication. $^{3}$

SCTT of the head of the bean/lactose test meal was defined as the time taken from gavage to a sustained increase in the hydrogen concentration in the rats' environment. This was defined as an increase of $2 \mathrm{ppm}$ sustained for at least three consecutive 10 minute readings. ${ }^{2}$ This was assumed to occur when the unabsorbable carbohydrate component of the meal reached the colon and was fermented by the colonic bacteria. ${ }^{13} 14$

\section{STATISTICAL ANALYSIS}

The differences in transit times produced during either saline or lipid infusion into the ileum was assessed using the Student's paired $t$ test. Data are shown as mean (SEM).

\section{Results}

Acute infusion of palm oil into the ileum caused a highly significant delay in the transit time of the head of the bean meal compared with infusion of the emulsifier (195 (12) $\min v$ 95 (7) min; palm oil $v$ emulsifier; $n=20$; $\mathrm{p}<0 \cdot 001)$.

Chronic infusion of palm oil was associated with a reduction of this lipid induced delay in 


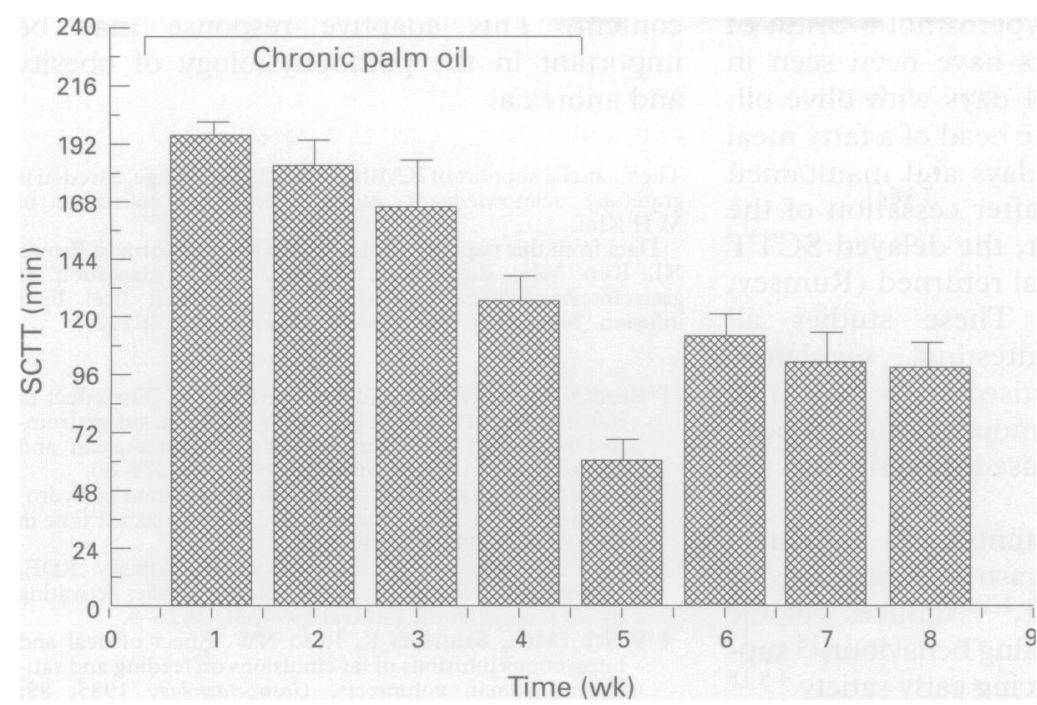

Figure 1: Histograms showing effects of an acute (weeks 1-8) palm oil infusion into the distal small intestine during chronic intermittent palm oil infusion into the distal small intestine (weeks $1-4 ; n=10$ ) and after the chronic palm oil infusion had ended (weeks 5-8; $n=5$ ), on SCTT of the head of the meal.

SCTT of an acute palm oil infusion. SCTT of the head of the test meal during an acute ileal infusion of palm oil gradually shortened to reach values similar to those obtained during ileal infusion of emulsifier (Fig 1). At week 4 when the group of rats receiving chronic intermittent palm oil infusion was challenged with an acute infusion of emulsifier, control values for SCTT were obtained (96 (7) $\mathrm{min}$ ). SCTT of the head of the test meal did not change throughout the four week period of chronic intermittent emulsifier infusion (Fig 2). Chronic infusion of the emulsifier was not accompanied by any change in the transit time of the head of the meal during an acute ileal infusion of emulsifier (Fig 2) or during acute ileal infusion of lipid (184 (10) $\min v 179$ (8) $\min$ ).

After the chronic intermittent infusions had finished, the response to an acute infusion of emulsifier in the five rats that had received chronic emulsifier infusion SCTT of the head of the meal remained the same (Fig 2). The

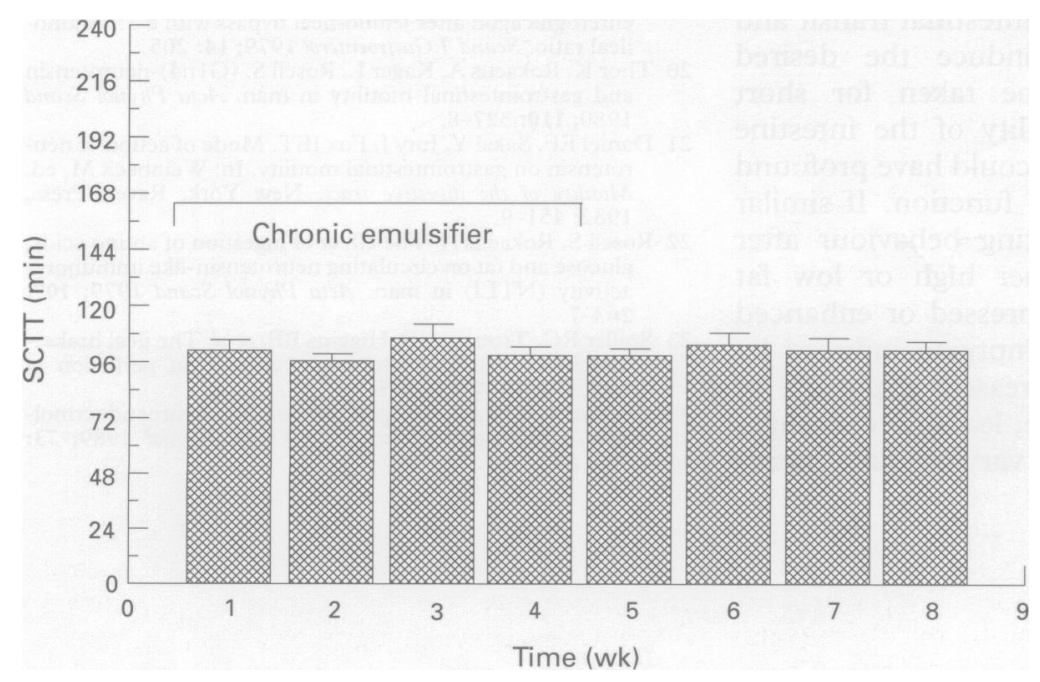

Figure 2: Histograms showing effects of an acute (weeks 1-8) infusion of physiological emulsifier into the distal small intestine during chronic intermittent physiological emulsifie into the distal small intestine (weeks $1-4 ; n=10$ ) and after the chronic emulsifier infusion had ended (weeks 5-8; $n=5$ ), on SCTT of the head of the meal. lipid induced delay in SCTT of the head of the meal did not return in the five animals that had received chronic intermittent lipid infusion, during the four weeks after the chronic lipid infusion had ended (Fig 1). SCTT of the head of the meal was significantly shorter than control values during ileal infusion of emulsifier $(p<0.05)$ in the week after chronic palm oil infusion had finished.

\section{Discussion}

The results from this study show that the delay in SCTT induced by an acute infusion of lipid into the ileum is abolished by chronic infusion of palm oil into the distal small intestine. This desensitisation occurred gradually over a period of four weeks, and was not reversed for four weeks after the chronic lipid infusion had ended. Stomach to caecum transit values during infusion of the emulsifier alone were unaffected by the chronic lipid infusion showing that the change in transit was not caused by a global change in gastrointestinal motor activity but was related to a specific change in the acute response to fat. It is unlikely, for example, that the early rise in environmental hydrogen could be caused by overgrowth of bacteria in the small intestine resulting from delayed small intestinal motility induced by the chronic lipid infusion as this would also produce an early hydrogen response to ileal infusion of the emulsifier alone. Also we have previously shown that protein hydrolysate infused into the distal small intestine delays the passage of the head of a meal through the stomach and the small intestine. ${ }^{15}$ This delay in SCTT of the head of the meal induced by distal small intestinal infusion of protein remained in rats four weeks after the discontinuation of the chronic intermittent infusion of lipid (unpublished findings), suggesting a specific adaptation to lipid within the gastrointestinal tract. It is interesting, however, that the response to an acute infusion of palm oil into the distal small intestine - that is, delayed SCTT - had not recovered after four weeks, and indeed the week (week 5) after the chronic palm oil infusion had finished, SCTT was significantly shorter than the control transit time. This had returned to control values one week later (week 6 ). It may be that induction of the adaptive response to chronic palm oil infusion can be achieved over a shorter time course than the reversal of the adaptive response after cessation of the chronic palm oil. The reason for this remains unclear.

These results showing adaptation of intestinal receptors that influence the mechanisms regulating gastrointestinal motility and transit are similar to studies in human volunteers investigating the effects of ingesting meals high in fat and glucose content over prolonged periods of time on gastric emptying and small intestinal transit. Ingestion of a high fat diet for two weeks increased the rate of gastric emptying and mouth to caecum transit of a fatty meal ${ }^{11}$ whereas increased intake of glucose for three days accelerated 
gastric emptying of a hyperosmotic drink of glucose. ${ }^{12}$ Similar effects have been seen in rats gavaged daily for 14 days with olive oil. The delay in SCTT of the head of a fatty meal was abolished by seven days and maintained at 14 days. Seven days after cessation of the olive oil gavage, however, the delayed SCTT of the head of a fatty meal returned (Rumsey, unpublished findings). These studies all suggest that small intestinal regulatory mechanisms are desensitised by a period of exposure to increased amounts of lipid both in the diet and when infused directly into the small intestine.

Lipid is a powerful stimulus in the small intestine. It delays gastric emptying, ${ }^{416}$ slows small bowel transit, ${ }^{116}$ induces colonic motility, ${ }^{17}$ and changes eating behaviour, ${ }^{18}$ suppressing hunger and inducing early satiety. ${ }^{4518}$ It is difficult, however, to speculate on the possible mechanisms of this adaptive response, as the transduction of fat signals is not clearly understood. One possibility is that the lipid may interact with specialised enteroendocrine cells to release transmitters, which may influence gastrointestinal motility, either by depolarising afferent neurones and activating neural reflexes or circulating in the blood stream as endocrine agents. Thus adaptation could occur by down regulation in lipid receptors or by a reduction in the release of mediators such as polypeptide $Y$, enteroglucagon, neurotensin or cholecystokinin all of which have been shown to be released by the presence of lipid within the small intestine. ${ }^{19-24}$ Alternatively down regulation of receptors on afferent neurones or modulation of receptors at the effector site on the gastrointestinal smooth muscle or myenteric nerve plexus may induce intestinal motor adaptation, although this would be expected to change the transit of the emulsifier alone.

The results from the study suggest that continual exposure of the distal small intestine to lipid changes gastrointestinal patterns. These may be more pronounced in rats than in humans because they have a low fat content in their diet. Therefore the use of lipid capsules to control gastrointestinal transit and eating behaviour may induce the desired effect but could only be taken for short lengths of time. The ability of the intestine to adapt the fat, however, could have profound effects on gastrointestinal function. If similar results are seen with eating behaviour after chronic exposure to either high or low fat diéts hunger may be suppressed or enhanced and changes in gastric emptying induced by either increased or decreased exposure of lipid to the small intestine, leading to changes in tolerance to diets varying in energy content. This adaptive response may be important in the pathophysiology of obesity and anorexia. The financial support of KABI INVENT, Huddinge, Sweden is
gratefully acknowledged, and the technical assistance of gratefully

Data from this paper are published in abstract form in Brown NJ, Kim MH, Rumsey RDE, Read NW. Adaptation of gastrointestinal transit to chronic intermittent ileal lipid infusion. Fournal of Gastrointestinal Motility 1992; 4: 212.

1 Read NW, McFarlane A, Kinsman RI, et al. The effect of infusion of nutrient solutions into the ileum on gastrointestinal transit and plasma levels of neurtotensin and enteroglucagon. Gastroenterology 1984; 86: 274-80.

2 Brown NJ, Rumsey RDE, Read NW. Adaptation of hydrogen analysis to measure stomach to caecum transit time in gen analysis to measure stomach

3 Brown NJ, Read NW, Richardson A, Rumsey RDE, Bogentoft C. Characteristics of lipid substances activating the ileal brake in the rat. Gut 1990; 31: 1126-9.

4 Welch IMcL, Saunders K, Read NW. Effect of ileal and intravenous infusions of fat emulsions on feeding and satiety in human volunteers. Gastroenterology 1985; 89: 955-65.

5 Welch IMcL, Cunningham KM, Read NW. Regulation of gastric emptying by ileal nutrients in man. Gastroenterology 1988; 94: 401-4.

6 Holt S, Ford MJ, Grant S, Heading RC. Abnormal gastric emptying in primary anorexia nervosa. Br F Psychol 1981; 139: $550-2$.

7 Robinson PH, Clarke M, Barratt J. Determinants of delayed gastric emptying in anorexia nervosa and bulimia nervosa. gastric emptying in ano

8 Rigaud D, Bedig G, Merrouche M, Vulpillat M, Bonfils S, Apfelbaum M. Delayed gastric emptying in anorexia nervosa improved by completion of a renutrition program. Dig Dis Sci 1988; 33: 919-25.

9 Johansson C, Ekeland K. Relation between body weight and the gastrointestinal handling of an oral caloric load. Gut 1976; 17: 456-62.

10 Wright RA, Kim YC, Fleeman C. Solid and liquid gastric emptying in obese patients. Gastroenterology 1981; 180: 1320 .

11 Cunningham KM, Daly J, Horowitz $M$, Read NW. Gastrointestinal adaptation to diets of differing fat Gastrointestinal adaptation to diets of differing fat
compositions in human volunteers. Gut 1991; 32: 483-6.

12 Cunningham $\mathrm{K}$, Horowitz $\mathrm{M}$, Read NW. The effect of short-term dietary supplementation with glucose on gastric emptying in humans. Br $\mathcal{F}$ Nutr 1991; 65: 15-9.

13 Read NW, Miles CA, Fisher D, et al. Transit of a meal through the stomach, small intestine and colon in normal subject and its role in the pathogenesis of diarrhoea. Gastroenterology 1980; 79: 1276-82.

14 Bond $\mathrm{JH}$, Levitt $\mathrm{MD}$. Investigation of small bowel transit time in man utilising pulmonary hydrogen $\left(\mathrm{H}_{2}\right)$ measurements. F Clin Invest 1975; 85: 546-55.

15 Brown NJ. The regulation of gastrointestinal transit in the rat [Thesis]. Sheffield: University of Sheffield, 1988

16 Brown NJ, Rumsey RDE, Bogentoft C, Read NW. The effect of adrenoceptor antagonists on the ileal brake effect of adrenoceptor antagonists on the ileal brake
mechanism in the rat. Br $\mathcal{F}$ Pharmacol 1992; 105: 751-5.

17 Battle WM, Cohen S, Snape WJ. Inhibition of postprandial colonic motility after ingestion of an amino acid mixture. Dig Dis Sci 1980; 25: 647-52.

18 Sepple CP, Read NW. Effect of prefeeding lipid on food intake and satiety in man. Gut 1990; 31: 158-61.

19 Holst JJ, Sorenson TIA, Anderson AN, et al. Plasma enteroglucagon after jejuno-ileal bypass with a 3:1 jejunoileal ratio. Scand $\mathcal{F}$ Gastroenterol 1979; 14: 205.

20 Thor K, Rokaeus A, Kager L, Rosell S. (GIn4)-neurotensin and gastrointestinal motility in man. Acta Physiol Scand 1980; 110: 327-8.

21 Daniel EF, Sakai Y, Jury J, Fox JET. Mode of action of neurotensin on gastrointestinal motility. In: Weinbeck M, ed.
Motility of the digestive tract. New York: Raven Press, Motility of the

22 Rosell S, Rokaeus A. The effect of ingestion of amino acids, glucose and fat on circulating neurotensin-like immunoreactivity (NTLI) in man. Acta Physiol Scand 1979; 107; 263-7.

23 Spiller RC, Trotman IF, Higgins BE, et al. The ileal brake inhibition of jejunal motility after ileal fat perfusion in man. Gut 1984; 25: 365-74.

24 Dockray GJ. Regulatory peptides and the neuroendocrinology of brain-gut relations. $Q \mathcal{f}$ Exp Physiol 1989; 73: 703-27. 